\title{
Event-related brain potentials to grammatical errors and semantic anomalies
}

\author{
MARTA KUTAS and STEVEN A. HILLYARD \\ University of California at San Diego, La Jolla, California
}

\begin{abstract}
Event-related brain potentials (ERPs) were recorded while subjects silently read several prose passages, presented one word at a time. Semantic anomalies and various grammatical errors had been inserted unpredictably at different serial positions within some of the sentences. The semantically inappropriate words elicited a large N400 component in the ERP, whereas the grammatical errors were associated with smaller and less consistent components that had scalp distributions different from that of the N400. This result adds to the evidence that the N400 wave is more closely related to semantic than to grammatical processing. Additional analyses revealed that different ERP configurations were elicited by open-class ("content") and closedclass ("function") words in these prose passages.
\end{abstract}

In the natural discourse of any language, successive words are subject to both semantic and grammatical constraints that make some words more likely to occur than others. These contextual effects have a profound influence on the speed and accuracy of word recognition as revealed in lexical-decision (Fischler \& Bloom, 1979; Kleiman, 1980; Schuberth \& Eimas, 1977; Schuberth, Spoehr, \& Lane, 1981), threshold-detection (Morton, 1964; Tulving \& Gold, 1963), and pronunciation tasks (Stanovich, 1981; Stanovich \& West, 1979 , 1981; Underwood \& Bargh, 1982). In general, it has been shown that words that fit an established semantic or syntactic context can be recognized more quickly than words that are anomalous to or incongruous with preceding words. A number of models have been put forward to account for the interactions between stimulus information and context in word recognition (Becker, 1980; Becker \& Killion, 1977; Forster, 1976; Meyer, Schvaneveldt, \& Ruddy, 1975; Morton, 1980).

Differences in the processing of expected versus incongruous words can be demonstrated with a variety of other experimental techniques. For example, MarslenWilson and colleagues (Marslen-Wilson, 1975; MarslenWilson \& Tyler, 1975; Marslen-Wilson \& Welsh, 1978; Tyler \& Marslen-Wilson, 1977) have shown that the types of shadowing errors made while a subject repeats a tape-recorded message depend on whether the ongoing context is distorted at the lexical, syntactic, or semantic level. Similar effects have also been observed in word.

This research was supported by NSF Grant BNS80-05525 and Sloan Foundation Grant B1980-35. M. Kutas is supported by Research Scientist Development Award USPHS $1 \mathrm{~K} 02 \mathrm{MH0322/03}$. Thanks go to J. C. Phillips for technical assistance and to $\mathrm{J}$. C. Hansen for providing computer programs for data reduction and analyses. The author's mailing address is Department of Neurosciences, University of California at San Diego, La Jolla, California 92093. monitoring and mispronunciation-detection tasks (Cole \& Jakimik, 1978, 1980; Marslen-Wilson \& Tyler, 1980; Tyler \& Marslen-Wilson, 1981). During reading, dependent measures such as fixation or gaze durations (Ehrlich \& Rayner, 1981; Just \& Carpenter, 1980; McConkie, Zola, Blanchard, \& Wolverton, 1982), number of regressive eye movements (Carpenter \& Daneman, 1981 ; Carpenter \& Just, 1981), and number and type of oral reading errors (Danks \& Hill, 1981; Jacobson, 1973; Danks, Fears, Bohn, \& Hill, Note 1) are likewise sensitive to deviations from context. It is clear that the buildup of linguistic expectancies and the specialized processing that is accorded out-of-context words are important factors in language comprehension.

The role of contex tual factors in language can also be investigated through scalp recordings of the electrical activity that is elicited in the brain by word presentations. This approach stems from findings that several of the longer latency components of the event-related brain potentials (ERPs) are markedly sensitive to variations in stimulus expectancy for both verbal and nonverbal material (reviewed in Donchin, Ritter, \& McCallum, 1978, and Pritchard, 1981). In particular, a late positive wave elicited $300-500 \mathrm{msec}$ after relevant but unpredictable stimuli (the $\mathrm{P} 3$ or $\mathrm{P} 300$ component) is augmented in amplitude for increasingly improbable or unexpected stimuli. The making of lexical or semantic decisions about unpredictable words is associated with late positive ERPs in a variety of circumstances (Friedman, Simson, Ritter, \& Rapin, 1975; Kutas, McCarthy, \& Donchin, 1977; Polich, Vanasse, \& Donchin, 1981; Shelburne, 1972).

Over the past several years we have recorded ERPs associated with the violation of semantic expectancies during a reading task in which grammatically simple sentences were presented one word at a time (Kutas \& Hillyard, 1980a, 1980b, 1980c, 1982, in press; Kutas, Lindamood, \& Hillyard, in press). The ERPs to the 
final words in the sentence were distinctly different according to whether the word completed the sentence in an appropriate, meaningful way or whether it was semantically anomalous to the preceding context. The ERPs following appropriate words showed a broad positive shift, which appeared to consist primarily of the resolution of a prior contingent negative variation (CNV), whereas the semantically incongruous words elicited an additional negativity peaking at around $400 \mathrm{msec}$ over the posterior scalp (the N400). Control experiments showed that physically deviant stimuli such as words presented in boldface type (Kutas \& Hillyard, $1980 \mathrm{a}, 1980 \mathrm{~b}$ ) or complex colorful pictures presented at the ends of these sentences (Kutas \& Hillyard, in press) elicited late positive components of the $\mathrm{P} 300$ variety rather than a negative-going $\mathrm{N} 400$ component. Kutas and Hillyard (1980c) suggested that the N400 might be a physiological sign of the reader's continued processing of an unexpected semantic violation in attempt to arrive at a meaningful interpretation of the sentence.

The present study was aimed at investigating whether the N400 effect is specific to semantically deviant words or whether it is elicited by a broader class of unexpected words, in particular, words that are grammatically incorrect. Several types of grammatical errors were chosen for study on the basis of their being immediately evident upon presentation and yet preserving the meanings of the sentences in which they were embedded. These violations consisted primarily of errors in word-boundary morphemes that designated either word number (singular vs. plural) or verb tense (past vs. present). If the $\mathrm{N} 400$ is associated specifically with semantically inappropriate words, then we would not expect grammatical errors to yield an N400. On the other hand, if the N400 is associated with violations of linguistic relationships at any level, it should be present for both types of deviant words.

Another experimental goal was to determine whether the N400 could be elicited in a more natural reading situation. In our previous studies of this ERP, all the sentences used were seven words in length, successive sentences were unrelated to one another, and the semantic anomalies were restricted to the terminal position. The present experiment presented prose passages consisting of variable-length sentences, each passage dealing with a single topic. Semantic and grammatical anomalies occurred unpredictably at different serial positions within the sentences.

The presence of semantic incongruities at intermediate positions within sentences allowed tests of specific hypotheses about the relationship of the N400 effect to other types of ERPs. One possibility is that the $\mathrm{N} 400$ is simply a continuation of the CNV-like negativity that develops over the course of a sentence (Kutas \& Hillyard, 1980c); following the anomalous word, the subject may be anticipating a further word that will better complete the sentence or resolve the ambiguity, and this expectation could prolong the CNV. In this view, the N400 could be seen as either an extension of the CNV or a postimperative negative variation (PINV) that follows the CNV under certain circumstances. The incongruities that occur at intermediate sentence positions test for the presence of the N400 effect without the confound of CNV extension and/or resolution effects that may follow terminal words.

The intermediate semantic anomalies can also be used to examine the proposal that the N400 in the sentencereading task is actually the initial negative phase of a delayed N200-P300 complex (Polich et al., 1981; Ritter, Ford, Gaillard, Harter, Kutas, Nätänen, Polich, Renault, \& Rohrbaugh, in press). According to this view, the N400 might be an example of the more general N200 component to deviant or mismatching stimuli, which is typically followed by a P300 component when stimuli are attended. Proponents of this view (Prifchard, 1981) have suggested that Kutas and Hillyard (1980c) did not record an epoch long enough to observe the P300 elicited. In the present experiment, the ERPs to semantic anomalies were examined on a longer time base and in the absence of overlapping end-of-sentence potentials.

Since the words in the present experiment belonged to natural prose passages, they could readily be assigned to one of two major vocabulary categories-the so called closed-class ("function") and the open-class ("content") words. In brief, this distinction is between the major lexical items (e.g., nouns, verbs, and adjectives) that fall into the open-class category and the minor lexical items such as determiners ("the"), auxiliaries ("were," "have"), prepositions ("by," "to"), conjunctions ("and," "but"), and quantifiers ("all," "some") that belong to the closed class. Evidence from a variety of sources supports such a distinction in the vocabulary and its association with differences in cerebral organization (Bradley, 1978; Bradley, Garrett, \& Zurif, 1980; Friederici \& Schoenle, 1980; Zurif, 1980), although recent behavioral evidence on this point is inconsistent (Gordon \& Caramazza, 1982). To gain further evidence on the validity of the open/ closed class distinction, all the nondeviant words in the prose passages were assigned to the appropriate class, and ERP differences between them were examined.

\section{METHOD}

\section{Subjects}

Seventeen young adults (13 males, 4 females, age range $=$ 18-33 years) were paid for participating in the experiment. Sixteen of the subjects were right-handed according to selfreport and the Edinburgh Inventory (Oldfield, 1971), and 6 of these had left-handed relatives in their immediate family. The remaining subject was left-handed and had sinistral relatives.

\section{Stimuli \\ Words were displayed in the form of brightened dot matrices on a CRT controlied by an Apple 11 microcomputer. All words}


lasted $200 \mathrm{msec}$ and subtended a vertical angle of $0.4 \mathrm{deg}$ when the subjects sat approximately 53 in. from the screen.

\section{Recording Sy stem}

EEG activity was recorded from eight scalp electrodes, each referred to linked mastoids. Four electrodes were placed according to the International 10-20 convention (Jasper, 1958) at $\mathrm{Fz}, \mathrm{Cz}, \mathrm{Pz}$, and $\mathrm{Oz}$ sites; these are located on the midline of the head over frontal, central, parietal, and occipital cortical areas, respectively. Symmetrical frontal electrodes were placed over the left and right hemispheres, halfway between F7-T3 and F8-T4, respectively; over the left hemisphere, this electrode lay approximately over Broca's area. Symmetrical right and left temporoparietal electrodes were placed laterally (by $30 \%$ of the interaural distance) and $12.5 \%$ posteriorly to the vertex; over the left hemisphere, this electrode lay approximately over Wernicke's area. Eye movements and blinks were monitored via an electrode placed on the lower orbital ridge and referred to a right ex ternal canthal electrode.

The midline and lateral temporoparietal recordings were amplified with Grass 7P1 preamplifiers (system bandpass de to $40 \mathrm{~Hz}$, half-amplitude cutoff). The lateral frontal scalp placements and the electrooculogram (EOG) were amplified with Grass 7P1 preamplifiers that had 8-sec time constants.

The EEG, EOG, and stimulus-trigger codes were recorded on FM tape, and analog-to-digital conversion was performed offline by a PDP $11 / 45$ computer. A 1,024-msec epoch of EEG data beginning $100 \mathrm{msec}$ before the onset of each stimulus was analyzed at a sampling rate of $256 \mathrm{~Hz}$. A subset of these data were also analyzed on a longer time base $(7,109 \mathrm{msec}$ sampled at $36.6 \mathrm{~Hz}$ ) beginning $500 \mathrm{msec}$ before the onset of the first word in the sentence.

\section{Procedure}

The subjects were tested in one session that lasted 2.5 to $3 \mathrm{~h}$; while being tested, they reclined in a comfortable chair. Prior to the ERP recordings, each subject was given the Level II pronunciation and spelling subtests of the Wide Range Achievement Test (WRAT). Following that, they were told to read the simple stories that were presented on the screen, one word at a time. This material was taken from children's books (10-year-old level) and consisted of factual accounts of a number of topics (e.g., turtles, weather, cats). The subjects were forewarned that the text would contain some errors, such as words that were out of place or grammatical mistakes, but that their assigned task was to read the paragraphs silently in order to answer some multiple-choice questions about the subject matter at the end of each run. It was emphasized that no questions would pertain to any of the anomalies presented.

The words were presented on a CRT screen, occluded except for a rectangular slit in the center through which the words were viewed. The words within a sentence appeared sequentially at onset-to-onset intervals ranging from 640 to $760 \mathrm{msec}$, the last of which was followed by a period to indicate sentence completion. After a 2,100-msec delay, the next sentence was presented, and so on.

Each subject received five experimental runs, each run lasting approximately 10-15 min. Across all the runs, the subjects were shown 4,114 words contained within 365 sentences. The sentences varied in length from 3 to 28 words (mean $=11$, $\mathrm{SD}=4$ ). Of the 365 sentences, 164 were semantically congruous and grammatically correct. The remaining 201 sentences contained one, and only one, semantic or grammatical deviation. These deviations in the text were of the following types (see Appendix for further examples):

(1) Forty-five sentences ended with a semantically inappropriate content word (e.g., "Turtles are smarter than most reptiles but not as smart as mammals such as dogs or socks").

(2) Fifty-two sentences contained a semantically inappropriate content word in a position other than the beginning or end, generally between the third and final words (c.g., "Other well-known reptiles are snakes, lizards, eyeballs and alligators").

(3) One hundred and four of the sentences contained a grammatical error generally in a word-boundary bound morpheme. (a) In 64 sentences, a noun or a verb that should have been singular was plural, or vice versa ( $1 / 2$ function, $1 / 2$ content words). There were 39 instances in which the noun number was incorrect and 25 instances in which the verb number was incorrect (e.g., "As a turtle grows its shell grow too" and "Some shells is even soft"). (b) There were 40 sentences in which the verb tense was grammatically incorrect (e.g., "When clouds are cooled to a very low temperature snow may form. Ice begins to grew around invisible specks of dust that always float in the air"). The majority (7/8) of these errors occurred in content words.

Our previous studies (Kutas \& Hillyard, 1980a, 1980c, 1982, in press) have shown that semantic anomalies of the type illustrated above do not go unnoticed; most subjects have been capable of recognizing and recalling a fair proportion of the anomalous words when they have been provided with the carrier sentences (they have performed equally well for stimulus durations ranging between 100 and $200 \mathrm{msec}$ ).

In every case, the grammatical deviations were designed to be evident immediately upon their occurrence and to have only a minimal, if any, impact upon the meaning of the sentence in which they occurred. These text alterations occurred randomly within the sentences such that they could not be anticipated with certainty.

Every word in these texts except for the deviant or the final words in sentences was classified (and coded) as belonging to either a closed-class (i.e., "function") or open-class (i.e., "content") word category. Word classification was based on rules for differentiation and on examples from Bradley (1978); in all, there were 1,562 open-class and 2,031 closed-class words.

After each experimental run, the subjects were required to answer seven or eight multiple-choice questions covering the material they had just read. Five such tests, two on turtles, two on weather, and one on cats, were administered.

\section{RESULTS}

\section{ERPs to Terminal Semantic Anomalies}

The ERPs to the final words in the sentences (Figure 1) were similar in waveshape to the ERPs elicited by the preceding words, except that the former contained a much larger sustained positivity over the interval 300 to $900 \mathrm{msec}$, especially at the central and parietal sites. The ERPs to the semantically incongruous final words included an additional negative wave between 300 and $600 \mathrm{msec}$ poststimulus (N400), which was largest over parietal and occipital scalp sites. The ERP difference between the incongruous and appropriate endings (shaded areas in Figure 1) was highly significant over the interval $300-600 \mathrm{msec}$ [main effect of final word type, $\mathrm{F}(1,16)=29.39, \mathrm{p}<.001$, for area measured relative to $90-\mathrm{msec}$ prestimulus baseline]. A peak measure showed the $\mathrm{N} 400$ wave to incongruous endings (peaking at $410 \pm 18 \mathrm{msec}$ ) to be substantially more negative than the $90-\mathrm{msec}$ prestimulus baseline at most electrode sites (see Table 1).

\section{ERPs to Intermediate Semantic Anomalies}

The ERPs to semantically anomalous words in the interiors of sentences were also characterized by $\mathrm{N} 400$ components, which in this case were not superimposed upon large positive shifts (Figure 1). These N400 waves 

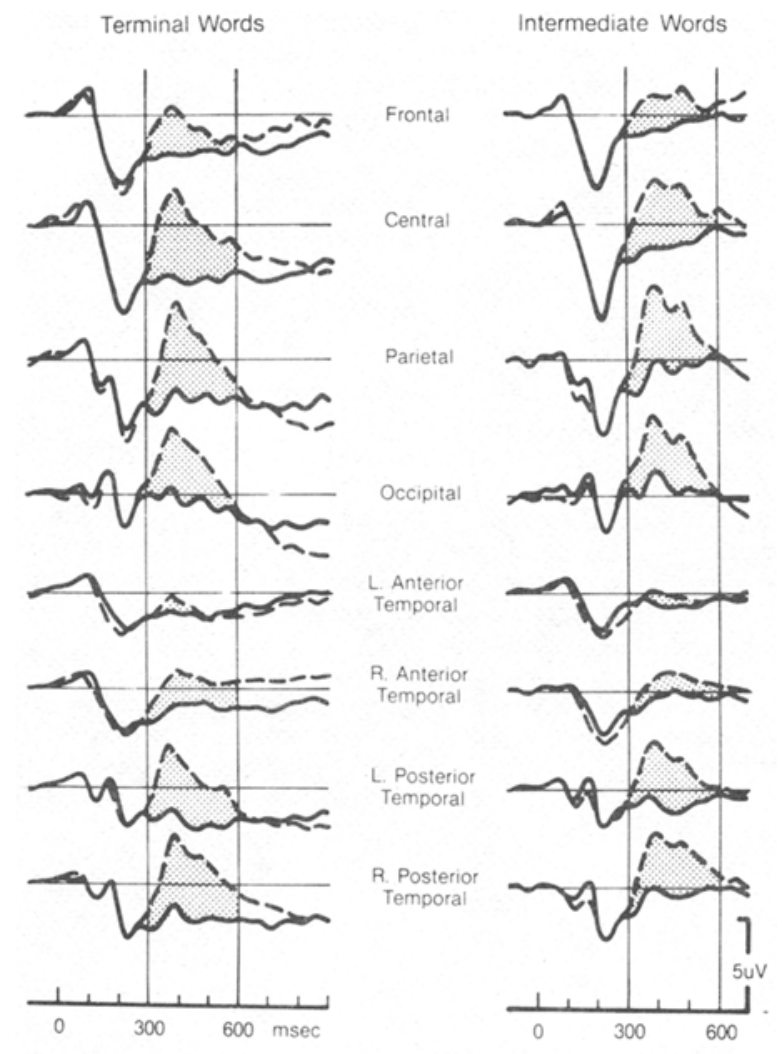

Semantically congruent word

- - Semantically incongruent word

Figure 1. Grand average ERPs over 17 subjects to semantically anomalous words at intermediate and terminal positions of sentences in the text (dashed lines). The superimposed waveforms (solid lines) are ERPs to semantically congruent words at corresponding positions. Content words that immediately preceded the intermediate semantic anomalies were chosen as the congruous words for these comparisons.

peaked significantly later $(433 \pm 18 \mathrm{msec})$ than those occurring at the ends of sentences [main effect of semantic anomaly position, $F(1,16)=12.31, \mathrm{p}<.003]$. As shown in Figure 1 (right column), this negativity in the $300-600-\mathrm{msec}$ range was markedly enlarged relative to the same measure in the average ERP to congruous (content) words that immediately preceded each semantic anomaly [main effect of word type, $F(1,16)=18.77$, $\mathrm{p}<.001]$.

Figure 1 underscores the similarity between the ERPs to semantic incongruities within and at the ends of sentences. In both cases, incongruity elicits a monophasic negativity peaking around $400 \mathrm{msec}$ over the posterior scalp, which is more prolonged over the right than over the left hemisphere. The similarity in scalp distribution of the N400 effect at the two positions can be seen by examining the incongruous minus congruous difference waves (shaded areas in Figure 1; Table 1).
Analyses of the area measurements of the 300-600-msec region of the difference ERPs for the intermediate and terminal words showed that the two did not differ significantly [main effect of semantic anomaly position, $F(1,16)=0.35$, n.s.; semantic anomaly position $x$ scalp site interaction, $F(7,112)=0.71$, n.s.]

The ERPs to semantically incongruous words in intermediate positions and to the words immediately preceding and following them are shown on a longer time base in Figure 2. The most distinctive aspect of the response to the semantic incongruity is the prominent negativity over the posterior regions of the scalp between 300-700 msec poststimulus. No positive swing after the $\mathrm{N} 400$ that would resemble a delayed $\mathrm{P} 300$ component is evident.

The very late positivity appearing $800-900 \mathrm{msec}$ after the anomaly appears to represent a pair of components that have peaks around 200 and $300 \mathrm{msec}$ and that are elicited by the word following the anomaly. The second positivity appears to be somewhat larger in the ERP to the word immediately following the semantic anomaly than in the ERP to the word that precedes it (see shaded areas in ERPs to words pre- and postanomaly, Figure 2). Comparison of the mean area of this parietal positivity (between 225-350 msec) in the ERPs to the words immediately preceding and following the semantic anomaly, however, showed them not to differ significantly [measured in ERPs on a longer time base described in section on $\mathrm{CNV}, \mathrm{F}(1,13)=3.30$, n.s.] .

Table 1

Amplitudes (in Microvolts) and Standard Errors of the N400 Peak and Difference Waveforms (Relative to 90-msec Prestimulus Baseline) at Different Scalp Locations to the Semantically Anomalous Words at Terminal and Intermediate Sentence Positions

\begin{tabular}{lccccc} 
Onddball ERPs to & \multicolumn{2}{c}{ Terminal } & & \multicolumn{2}{c}{ Intermediate } \\
\cline { 2 - 3 } Anomalies & Amplitude & SE & & Amplitude & SE \\
\hline Frontal & -2.4 & 0.8 & -3.4 & 0.8 \\
Central & -3.3 & 0.9 & -4.7 & 0.9 \\
Parietal & -4.6 & 0.9 & -5.9 & 0.8 \\
Occipital & -5.7 & 0.8 & -5.9 & 0.7 \\
L. Anterior Temporal & 1.3 & 0.5 & -1.6 & 0.4 \\
R. Anterior Temporal & -2.6 & 0.5 & -2.8 & 0.5 \\
L. Posterior Temporal & -3.4 & 0.8 & -3.9 & 0.5 \\
R. Posterior Temporal & -4.1 & 0.5 & -4.4 & 0.5 \\
& Difference Waveforms* & & \\
Frontal & -4.4 & 0.6 & -4.7 & 0.8 \\
Central & -6.2 & 0.6 & -6.5 & 0.9 \\
Parietal & -6.4 & 0.7 & -6.6 & 0.9 \\
Occipital & -5.2 & 0.7 & -5.1 & 0.6 \\
L. Anterior Temporal & -2.5 & 0.3 & -2.4 & 0.4 \\
R. Anterior Temporal & -3.7 & 0.4 & -3.3 & 0.3 \\
L. Posterior Temporal & -5.0 & 0.6 & -5.0 & 0.5 \\
R. Posterior Temporal & -5.5 & 0.6 & -5.1 & 0.5 \\
\hline
\end{tabular}

Note-ERP = event-related potential. $\quad *$ Difference waveforms formed by subtracting ERPs to congruous words from those to incongruous words at corresponding sentence positions /see Figure 1 legend). 


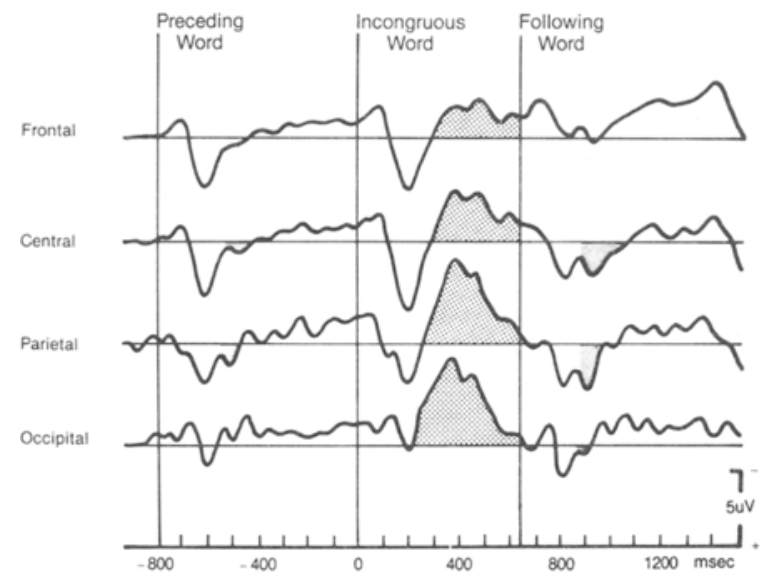

2. Grand average ERPs over all subjects elicited by the intermediate semantic anomalies and the preceding and following words.

Even if this late positivity had been significantly enhanced following the incongruous word, its very short duration and its equivalence of waveshape in the ERPs to the preceding and following words would rule against its being a very delayed $\mathrm{P} 300$ type of component in the ERP to the incongruous word.

\section{Lateral Distribution of the $\mathbf{N 4 0 0}$ to Semantic Oddballs}

As found previously, the late negativity elicited by semantic anomalies at the ends of sentences was asymmetric, being slightly larger and more prolonged over the right than over the left hemisphere (top half of Figure 3 ). This amplitude asymmetry was evident over both anterior and the posterior temporal regions [for area $300-600 \mathrm{msec}$, main effect of hemisphere $F(1,16)=$
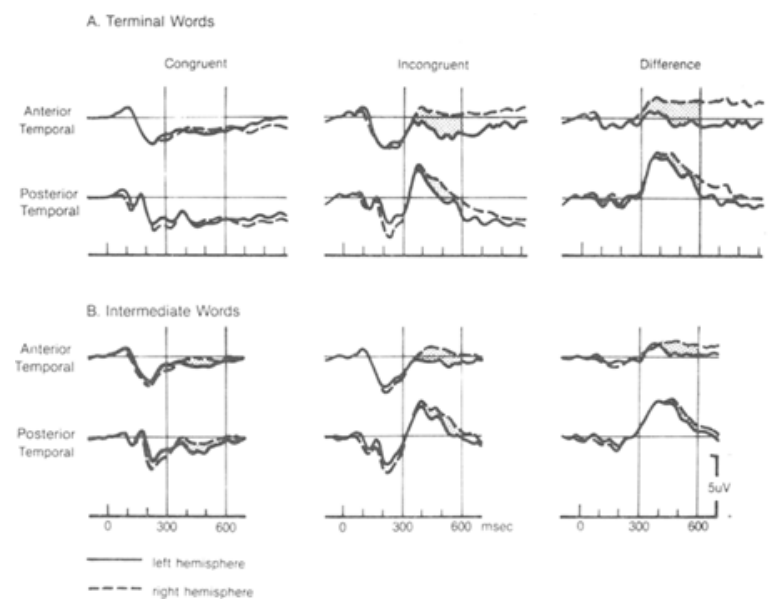

3. Lateral distributions of the grand average ERPs elicited by semantically anomalous words in intermediate and terminal positions and by congruent comparison words. At the right are difference ERPs obtained by subtracting the congruent from the incongruent ERPs.
$6.10, \mathrm{p}<.025]$. No significant asymmetry in the N400 region of the epoch was present in the ERPs to the semantically congruent terminal words. Hence, the rightgreater-than-left asymmetry was also present in the incongruent-minus-congruent difference ERP [for area 300-600 msec, main effect of hemisphere, $F(1,16)=$ $7.66, \mathrm{p}<.025]$.

Upon visual inspection, the N400 elicited by intermediate semantic anomalies also appeared to be asymmetric in its lateral scalp distribution (bottom half of Figure 3). This right-greater-than-left negativity, however, although statistically significant by a base-to-peak measure [main effect of hemisphere, $F(1,16)=8.75$, $\mathrm{p}<.009$ ], was not significant by the $300-600$-msecarea measure for either the constituent ERPs or the difference waves.

\section{ERPs to Grammatical Violations}

Morphological deviations were placed only at intermediate positions in the sentences. The ERPs elicited by the three types of grammatical errors are depicted in Figure 4, superimposed upon control ERPs elicited by nondeviant words. ${ }^{1}$ Visual inspection, as well as ANOVAs, of the area $300-600$ msec poststimulus indicates that the ERPs to the grammatical violations elicited very little late negativity; this $\mathrm{N} 400$ measure over all electrodes did not differ significantly from that elicited by the preceding comparison words for any of the types of deviations. The difference between the ERPs elicited by semantic and those elicited by grammatical deviations within these sentences is particularly clear at posterior temporal sites. The $\mathrm{N} 400$ seen in response to semantic anomalies (Figure 1) is not evident for any of these grammatical violations, which are quite similar to one another (see Table 2).

Although grammatical deviations did not elicit a posteriorly distributed N400, these ERPs were characterized by more late negativity than were the ERPs to the comparison words. Measurements of successive $100-\mathrm{msec}$ intervals from 200 to $700 \mathrm{msec}$ poststimulus for each type of grammatical error compared with its control revealed several regions of significant differences. The region $300-400 \mathrm{msec}$ was significantly more negative for all three types of grammatical deviations $(p<.05$ over all electrodes). In addition, significant differences were also obtained for the area $200-300 \mathrm{msec}$ for incorrect noun number $[F(1,16)=4.72, p<.05]$ and incorrect verb number $[F(1,16)=4.49, \mathrm{p}<.05]$, and for the $400-500-\mathrm{msec}$ region for incorrect noun number $[F(1,16)=6.97, p<.025]$. Given the number of statistical comparisons involved, these differences are considered marginal. Individual differences in waveforms were also greater for the grammatical than for the semantic deviations, and a single individual's ERPs to the different grammatical errors could differ markedly.

As for the responses to the words following the semantic anomalies, the ERPs elicited by the words immediately following all types of grammatical errors 


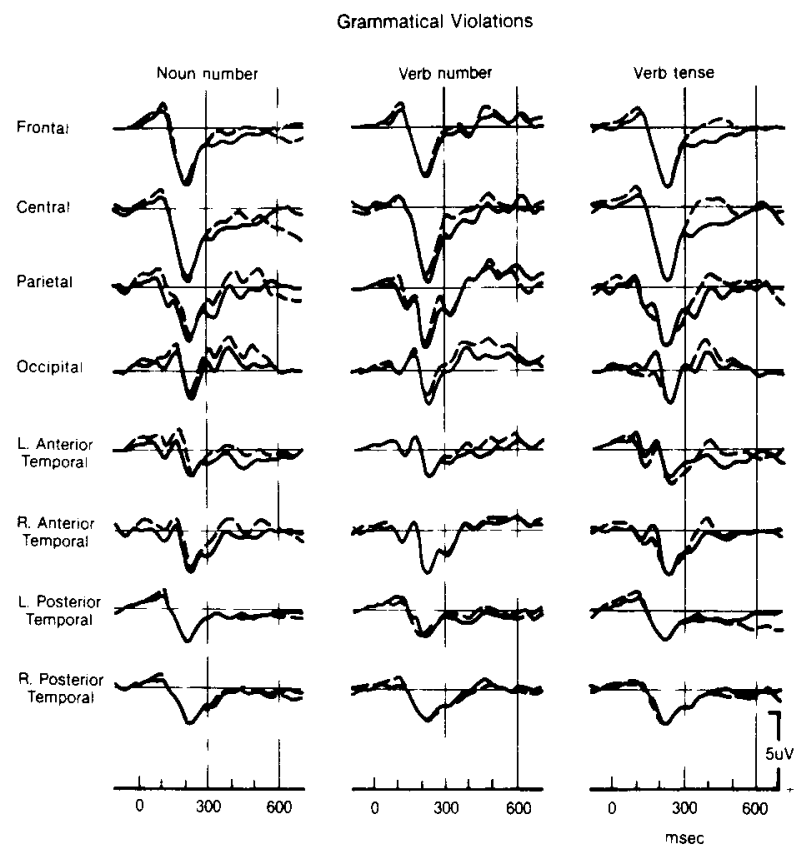

- control word

- - - grammatical violation

4. Grand average ERPs to each of the three types of grammatical errors. In each case, comparisons are made with ERPs elicited by semantically appropriate and grammatically correct control words occurring in comparable positions within the sentences. The proportion of function and content words in the control ERPs is equivalent to that in the grammatically deviant ERP with which it is compared.

appeared to have a positive peak at $300 \mathrm{msec}$ that was enhanced relative to its counterpart in the words immediately preceding these errors. This difference approached statistical significance at the parietal site $[\mathrm{F}(1,13)=4.42]$.

\section{Slow-Potential Shifts Across Sentences}

In order to ascertain whether the $\mathrm{N} 400$ shared a common neural generator with the slow potential shifts (e.g., the CNV) that develop over the course of a sen- tence (Kutas \& Hillyard, 1980c), it was important to compare the scalp distributions of these two types of ERPs. Because the sentences varied considerably in length, however, it was not possible to average across all of them and visualize any slow potential shift that may have been present. To obtain an estimate of the slow or steady potential shift across each sentence, an average ERP was computed over the first nine words of all sentences that were nine words in length or longer $(\mathrm{N}=260)$ for 14 of the 17 subjects in the experiment. Three subjects produced too many eye movements during the sentences to yield reliable waveforms.

The amplitude of the steady potential shift was taken as the mean voltage over the area $300-600 \mathrm{msec}$ after each word onset for the fourth through the eighth words in the sentences relative to a 500 -msec baseline prior to the first word. The means and standard errors of this measure are given in Table 3. Also shown for comparison are the 300- to 600-msec-area measures for the intermediate, semantically anomalous words and for the average of all the grammatically deviant words. These latter measures also were taken from waveforms averaged on the longer time base. It is evident that very little, if any, slow potential shift developed across the sentences. Moreover, the scalp distribution of this baseline shift, like that of the ERPs to the grammatically deviant words, was clearly different from the distribution of the N400 elicited by the semantically deviant words.

\section{ERPs to Open- and Closed-Class Words}

The general waveshapes of the ERPs to open and closed classes of words were quite similar to one another and included initial N100 and P200 components (Figure 5). However, the ERPs elicited by open-class words were characterized by a greater sustained positivity over most scalp sites. This difference, although small (12 microV), was highly significant when quantified as the mean voltage over $200-700 \mathrm{msec}$ poststimulus relative to a $90-\mathrm{msec}$ prestimulus baseline [main effect of word class, $F(1,16)=17.34, p<.001$, Table 4]. Moreover, this effect was more pronounced for recordings from the

Table 2

Waveform Area (in Microvolt-Milliseconds) and Standard Errors in the Interval 300 to 600 Msec in the Difference Waves Formed by Subtracting ERPs to Control Words From ERPs to Semantically and Grammatically Deviant Words

\begin{tabular}{|c|c|c|c|c|c|c|c|c|}
\hline \multirow[b]{3}{*}{ Location } & & & \multicolumn{6}{|c|}{ Grammatical Deviation } \\
\hline & \multicolumn{2}{|c|}{ Semantic Deviation } & \multicolumn{2}{|c|}{ Noun Number } & \multicolumn{2}{|c|}{ Verb Number } & \multicolumn{2}{|c|}{ Verb Tense } \\
\hline & Area & $\mathrm{SE}$ & Area & SE & Area & $\mathrm{SE}$ & Area & SE \\
\hline Frontal & -425 & 193 & -82 & 114 & -35 & 186 & -197 & 141 \\
\hline Central & -797 & 232 & -253 & 163 & -339 & 158 & -357 & 149 \\
\hline Parietal & -752 & 200 & -232 & 161 & -14 & 114 & -223 & 131 \\
\hline Occipital & -601 & 149 & -260 & 161 & -201 & 109 & -102 & 174 \\
\hline L. Anterior Temporal & -66 & 108 & -203 & 90 & -167 & 135 & -75 & 83 \\
\hline R. Anterior Temporal & -246 & 81 & -203 & 115 & -16 & 79 & -116 & 94 \\
\hline L. Posterior Temporal & -632 & 123 & -48 & 79 & -100 & 132 & 114 & 135 \\
\hline R. Posterior Temporal & -660 & 124 & -20 & 80 & 95 & 106 & 6 & 113 \\
\hline
\end{tabular}

Note-ERP $=$ event-related potential. 
Table 3

Mean Steady Potential Levels and Standard Errors Over Words 4-8 Compared With N400 Measure to Semantic and Grammatical Anomalies

\begin{tabular}{|c|c|c|c|c|c|c|}
\hline \multirow[b]{3}{*}{ Location } & \multirow{2}{*}{\multicolumn{2}{|c|}{$\begin{array}{c}\text { Average Across } \\
\text { Words 4-8 }\end{array}$}} & \multicolumn{4}{|c|}{ Incongruous } \\
\hline & & & \multicolumn{2}{|c|}{ Semantic } & \multicolumn{2}{|c|}{ Grammatical } \\
\hline & Mean & $\mathrm{SF}$ & Mean & $\mathrm{SE}$ & Mean & $\mathrm{SE}$ \\
\hline Frontal & 184 & 97 & -256 & 194 & 180 & 244 \\
\hline Central & 66 & 82 & -423 & 171 & 81 & 192 \\
\hline Parietal & 19 & 85 & -920 & 212 & -255 & 200 \\
\hline Occipital & 136 & 93 & 1200 & 148 & -308 & 230 \\
\hline L. Anterior Temporal & -38 & 54 & 99 & 137 & 180 & 99 \\
\hline R. Anterior Temporal & 76 & 42 & -280 & 108 & 233 & 82 \\
\hline L. Posterior Temporal & -7 & 76 & -1058 & 214 & -144 & 163 \\
\hline R. Posterior Temporal & 10 & 62 & -905 & 156 & -114 & 132 \\
\hline
\end{tabular}

Note-For each word, the measure is Area $300-600 \mathrm{msec}$ (in microvolt-milliseconds) relative to 500-msec baseline prior to the first word.

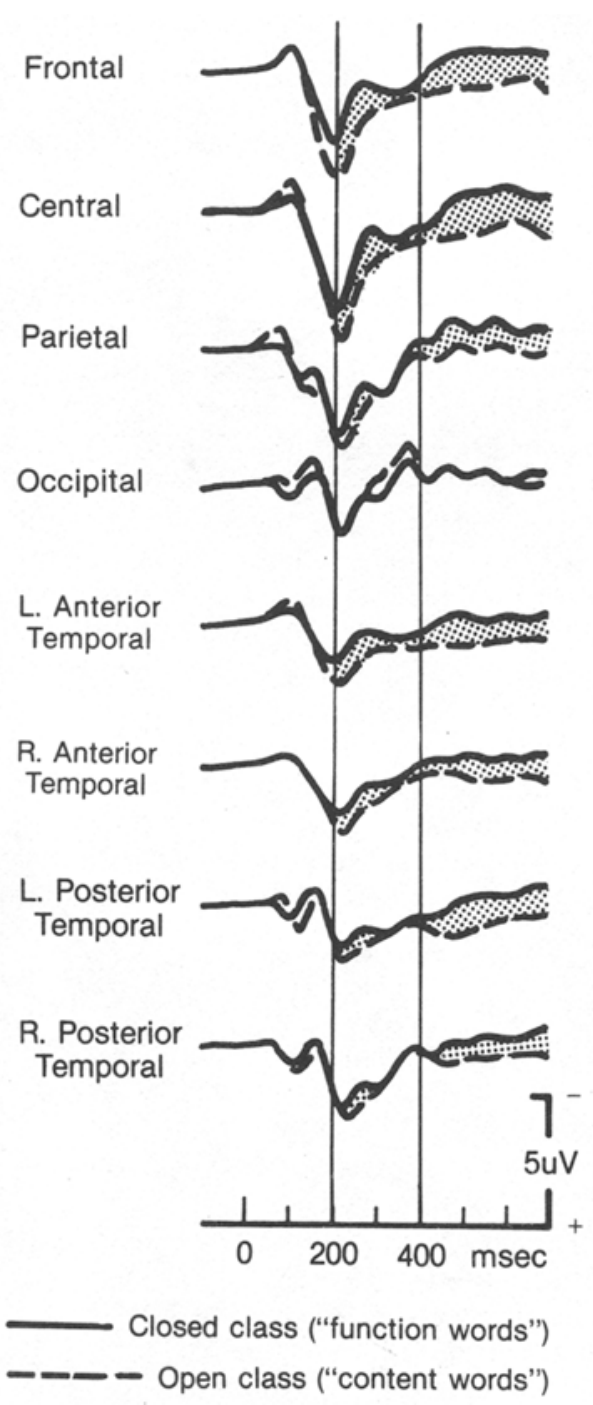

5. Grand average ERPs to open- and closed-class words across all sentence positions, except for terminal words. anterior than for those from the posterior regions of the scalp [word class $x$ scalp site interaction, $F(7,112)=$ $9.22, \mathrm{p}<.001]$ and, in fact, was reversed in some cases at the parietal and in most cases at the occipital electrode sites.

The lateral distribution of this sustained positivity also differed between function and content words. The left-right hemispheric differences in these ERPs were quantified as the area of the region $400-700 \mathrm{msec}$ poststimulus (Table 4). ${ }^{2}$ Although, overall, the left-hemisphere ERP was more positive than that for the right hemisphere [main effect of hemisphere, $F(1,16)=6.01$, $\mathrm{p}<.025$ ], there was also a significant word class $\mathrm{x}$ hemisphere interaction $[\mathrm{F}(1,16)=11.03, \mathrm{p}<.004]$, reflecting a relatively greater left-hemisphere positivity in the ERP to content words. As reported previously, the degree of left-right asymmetry in this late positivity was influenced by the subject's familial history of left-handedness (Kutas \& Hillyard, 1980a). For content words, the left-hemisphere ERP was significantly more positive than the right-hemisphere ERP for the 10 right-handers without left-handed relatives [main effect of hemisphere, $F(1,9)=13.95, p<.004$ ], whereas the ERPs from the six right-handers having left-handed relatives showed an opposite, but nonsignificant, trend.

\section{Behavioral Data: Multiple-Choice Questionnaire}

The subjects chose the correct answer for 78\% (range $=67 \%-90 \%$ ) of the 39 questions presented across the five experimental runs.

\section{DISCUSSION}

Semantically anomalous words embedded in simple, connected prose passages elicited a distinct N400 component that was broadly distributed over central, posterior, and temporal scalp regions, as had been found in previous experiments using isolated sentences (Kutas \& 
Table 4

Area Measures (in Microvolt-Milliseconds) and Standard Errors of ERPs to Function and Content Words Relative to a 90-msec Prestimulus Baseline

\begin{tabular}{|c|c|c|c|c|c|c|c|c|}
\hline \multirow[b]{3}{*}{ Location } & \multicolumn{4}{|c|}{ Area $200-700 \mathrm{msec}$} & \multicolumn{4}{|c|}{ Area $400-700 \mathrm{msec}$} \\
\hline & \multicolumn{2}{|c|}{ Function } & \multicolumn{2}{|c|}{ Content } & \multicolumn{2}{|c|}{ Function } & \multicolumn{2}{|c|}{ Content } \\
\hline & Area & $\mathrm{SE}$ & Area & SE & Area & SE & Area & SE \\
\hline Frontal & -7 & 97 & 549 & 185 & -207 & 44 & 158 & 100 \\
\hline Central & 180 & 92 & 719 & 183 & 133 & 47 & 226 & 106 \\
\hline Parietal & 105 & 111 & 437 & 148 & -221 & 48 & 41 & 99 \\
\hline Occipital & -103 & 118 & -107 & 123 & -169 & 47 & -99 & 67 \\
\hline L. Anterior Temporal & 66 & 50 & 460 & 103 & -60 & 24 & 212 & 49 \\
\hline R. Anterior Temporal & 136 & 141 & 410 & 112 & -47 & 22 & 125 & 57 \\
\hline L. Posterior Temporal & 127 & 59 & 470 & 93 & -77 & 31 & 222 & 63 \\
\hline R. Posterior Temporal & 204 & 68 & 399 & 80 & -65 & 26 & 104 & 55 \\
\hline
\end{tabular}

Note-ERP $=$ event-related potential.

Hillyard 1980a, 1980c, 1982, in press). In contrast, the grammatical errors were associated with a much smaller and less consistent late negativity that also differed in scalp topography, being much reduced over posterior temporal areas. These results add to the evidence that a large N400 is specific to words that are unexpected or inappropriate in semantic content and suggests that grammatical aberrations are processed in a different fashion (either qualitatively or quantitatively) from such semantic deviations.

These conclusions must be qualified, however, by the possibility that the grammatical errors used in this experiment were not as salient as the semantic anomalies and may have gone unnoticed in some cases. This seems unlikely for a number of reasons. Although these deviations were chosen so as not to disrupt the overall comprehensibility of the passage, they were intended to be instantly recognizable, particularly for the oneword-at-a-time mode of presentation with $700-\mathrm{msec}$ interword intervals. Moreover, the subjects were warned in advance that various grammatical errors would be sprinkled throughout the text, and nearly all reported having noticed many such errors. Nonetheless, it is possible that more blatant grammatical errors such as reversals of word order or incorrect parts of speech might elicit more substantial ERP correlates. The latter types of errors have been shown to have a marked impact on oral reading performance (Danks \& Hill, 1981) and on speeded recognition of ungrammatical sentences (Moore \& Biederman, 1979).

Questions could also be raised about the appropriateness of the control words that were used to elicit ERPs to be compared with the ERPs to the deviant words in intermediate sentence positions. Although, in one sense, it would have been ideal to compare ERPs to the same words when they were and were not anomalous (or grammatical), we wanted to avoid repetition of the same words in different segments of the text because this might have altered the subjects' expectancies and led them to pay special attention to the recurring words. A further problem with using the same words as anomalies and controls was that we wanted the semantic anomalies to be incongruous with the entire passage, as well as with the particular sentence in which it occurred; this would have been hard to accomplish given the thematic nature of the passages. Accordingly, we decided to use the words immediately preceding the anomalous words as their controls, selecting them so as to maintain about the same proportion of function and content words in both sets. Although this choice of control words may have allowed some degree of uncontrolled ERP fluctuation due to variations in word length, part of speech, etc., it is clear that such effects could not account for the marked ERP differences between semantic anomalies and grammatical errors.

These results bear on the question of the separability of semantic and syntactic processing levels and their respective roles in comprehension. Although semantic and syntactic violations have been found to produce very similar temporal patterns of disruption during oral reading (Danks \& Hill, 1981), there is ample evidence supporting the view that the two levels can have separable influences on sentence comprehension (Danks, 1969; Marks \& Miller, 1964; Shannon, 1973; Wang, 1970). The finding of an N400 component associated with semantic, but not with grammatical, anomalies is consistent with the hypothesis of separate modes of processing.

The N400 component elicited by semantic anomalies in intermediate sentence positions appeared virtually identical to that produced by terminal anomalies, except for a modest 20-msec delay in peak latency. The $\mathrm{N} 400$ at all sentence positions thus appeared to be synchronized to the onset of the anomalous word, suggesting that its incongruity was realized and evaluated immediately upon presentation. This interpretation is in accordance with the hypothesis that successive words are accessed from the lexicon and integrated with the preceding context (at least to the extent that their anomaly is recognized) as soon as possible after they have occurred (Carpenter \& Daneman, 1981; Just \& Carpenter, 1980; Marslen-Wilson, Tyler, \& Seidenberg, 1978; Tyler \& Marslen-Wilson, 1977) rather than being held in a buffer until several eye fixations (Bouma \& 
deVoogd, 1974) or the end of the sentence has occurred.

\section{Relation of N400 to Other ERPs}

The presence of clearly peaked N400 waves to the intermediate anomalies rules out the possibility that this negativity is simply a continuation of a steady potential shift (such as a CNV) developing over the course of the sentence. Indeed, unlike previous experiments in which substantial CNVs were elicited during seven-word sentences (Kutas \& Hillyard, 1980b, 1980c), no appreciable slow potential shifts arose during these variable-length sentences contained in connected prose passages. The minimal baseline shifts that were observed had a very different scalp distribution from that of the central-posterior $\mathrm{N} 400$, which arose sharply above the baseline by 4.5 microV. If the $\mathrm{N} 400$ is a member of the CNV-like family of slow potentials, it must represent a phasic augmentation of the steady potential level rather than its continuation. To our knowledge, such an effect has never been demonstrated for any type of CNV.

It also has been suggested that the $\mathrm{N} 400$ may be a delayed manifestation of the $\mathrm{N} 2$ or $\mathrm{N} 200$ component that occurs in association with the P300 wave after many types of surprising or informative stimuli (Polich et al., 1981; Pritchard, 1981; Ritter et al., in press). This raises a difficult problem of classification, since the defining properties of the N200 family of potentials have yet to be specified or agreed upon. Typically, an N200 component (150-300 msec) is elicited by taskrelevant stimuli that occur unexpectedly and is usually followed by a much larger P300 component (Donchin, Ritter, \& McCallum, 1978). This type of N200 has a modality-specific scalp distribution and has been linked with processes of stimulus discrimination (Ritter, Simson, \& Vaughan, 1983; Ritter, Simson, Vaughan, \& Friedman, 1979; Simson, Vaughan, \& Ritter, 1977). A physically deviant stimulus that has no assigned task relevance may in some cases elicit enhanced negativities in the 200-300-msec range, but again these are generally followed by large P300 waves (Courchesne, Courchesne, \& Hillyard, 1978; Courchesne, Hillyard, \& Galambos, 1975; Kutas \& Hillyard, 1980b; Neville, Snyder, Woods, \& Galambos, 1982; Roth, Ford, \& Kopell, 1978). Thus, the absence of a subsequent late positivity of the P300 variety (see Figure 2) sets the N400 apart from many of the late negativities that have been termed $\mathrm{N} 2$ or N200. In fact, we know of no reported instances in which a physically deviant or mismatching stimulus in an attended sequence of visual stimuli has elicited an N200 without a complementary $\mathrm{P} 300 .^{3}$

In the auditory modality, there have been reports of an N2/N200 component to physically deviant stimuli that is not followed by a large, late positivity when the stimulus sequence is unattended (Ford \& Hillyard, 1981; Nääänen, Gaillard, \& Mantysalo, 1980; Näätänen, Simpson, \& Loveless, 1982; Snyder \& Hillyard, 1976; Squires, Squires, \& Hillyard, 1975). However, this component occurs much earlier than the $\mathrm{N} 400$ (between 130-200 msec) and has a frontocentral scalp distribu- tion. For these reasons, and because it is difficult to believe that the cognitive processes elicited by an unattended shift in a tone's physical parameters would resemble those elicited by a semantically anomalous word, it seems unlikely that the N400 is "equivalent" in any meaningful sense to this type of N200. If the various types of $\mathrm{N} 200$ waves and the $\mathrm{N} 400$ all belong to a general class of "mismatch negativities" (Näätánen et al., 1980; Naatänen et al., 1982), then the defining properties of this class still need to be worked out. At present, it seems appropriate to consider these late negativities that display such diverse properties as separate components, probably with different cognitive correlates, rather than assuming them all under a global heading such as N200 or mismatch negativity.

Late negative components resembling the N400 have been observed in a number of experiments that engage semantic processing. For example, in experiments requiring semantic category judgments, words that did not belong to the category expected by the subject elicited additional late negativity between $300-500 \mathrm{msec}$ in relation to words that did belong (Boddy \& Weinberg, 1981; Polich et al., 1981). Similarly, Fischler, Bloom, Childers, Roucos, and Perry (1983) recorded ERPs to the final words of sentences of the form "An X is a Y" or "An X is not a Y." They found that an enhanced negativity between $300-500 \mathrm{msec}$ was elicited whenever the two noun arguments of a sentence were discrepant, irrespective of the truth or falsity of the proposition. Finally, Ritter et al. (1983) also noted a negativity around $400 \mathrm{msec}$ in response to an infrequent word category in a discriminative reaction time task.

Late negative components having an anterior distribution have been reported to follow unexpected words that subjects were required to identify orally or in writing (Neville, Kutas, \& Schmidt, 1982; Stuss, Sarazin, Leech, \& Picton, 1983). If some or all of these various late negativities are indeed equivalent to the N400 recorded in the present experiment, it would appear that this ERP may be elicited whenever a word is unexpected in a given semantic context and that an outright semantic incongruity is not a prerequisite. This view is consistent with recent evidence that the amplitude of $\mathrm{N} 400$ to congruous words at the ends of sentences is graded as an inverse function of the subject's expectancy for those words as assessed by a cloze probability measure (Kutas, Lindamood, \& Hillyard, in press). Thus, the $\mathrm{N} 400$ appears to be a sensitive indicator of the relationship between a word and its context. The present data strengthen the case that the critical feature of this relationship is semantic rather than grammatical in nature.

\section{Open- and Closed-Class Words}

Different ERP configurations were elicited by openclass (content) and closed-class (function) words. The ERPs to content words displayed a greater positive shift in the recording epoch from 200 to $700 \mathrm{msec}$ 
poststimulus than did the function-word ERPs; this difference was most pronounced over the frontal regions of the scalp and, in fact, was reversed at the occipital leads in a number of subjects. These ERPs also differed in their lateral distribution. The ERPs elicited by closedclass words were generally symmetrical over the two cerebral hemispheres, whereas the ERPs to open-class words included a late positivity in the $400-700-\mathrm{msec}$ range that was greater over the left than over the right hemisphere.

It is tempting to conclude that these ERP differences are directly related to the functional roles that have been ascribed to these lexical classes; that is, whereas content words generally bear reference and carry the major semantic information load, function words provide syntactic structure by signaling relations between content words. However, the words belonging to these two categories also differed along other important dimensions that were not controlled in the present study (for discussion, see Haber \& Schindler, 1981). For example, from a purely descriptive point of view, function words form a rather small and inflexible set of short words that have a high frequency of usage in the English language. In contrast, content words form a large class of words that is open to new members; they vary greatly in length, as well as in frequency of usage. It is not possible to decide on present evidence which of these or other differences is crucial (necessary and/or sufficient) to elicit the ERP differences observed (see also Kean, 1977, and Swinney, Zurif, \& Cutler, 1980). Thus, the ERP difference between function and content words could well arise from one of these other aspects of the word classes rather than from the fundamental (but controversial) division in the lexicon that has been proposed.

There are several lines of evidence that suggest that function and content words carry differing amounts of information (in the Shannon, 1973, sense) and are not processed equivalently. For example, content words are less predictable than function words in a cloze procedure (Aborn, Rubenstein, \& Sterling, 1959), and it is probably for that reason that most content words are fixated during free reading, whereas a greater proportion of function words are skipped (Just \& Carpenter, 1980). This is consistent with the finding that common function words (such as "and" and "the") serving as targets in a detection task are frequently missed when placed in an appropriate contextual setting (Drewnowski \& Healy, 1977). Similarly, in a prose passage, a target letter is more readily found if it is embedded in a content rather than in a function word (Schindler, 1978). Gaze durations are also appreciably longer for content than for function words-an observation that Just and Carpenter (1980) linked to a more extensive processing of content words. However, even within content words, short words that occur with high frequency are more often overlooked or fixated for a shorter duration than are longer, low-frequency words. The enhanced late positivity over frontocentral regions of the scalp for content words relative to function words may thus reflect the differential amount or duration of processing afforded to words of the two types.

\section{REFERENCE NOTE}

1. Danks, J. H., Fears, R., Bohn, L., \& Hill, G. O. Comprehension processes in oral reading. Paper presented at the meeting of the Psychonomic Society, San Antonio, Texas, 1978.

\section{REFERENCES}

Aborn, M., Rubenstein, H., \& Sterling, T. C. Sources of contextual constraint upon words in sentences. Journal of Experimental Psychology, 1959, 57, 171-180.

Becken, C. A. Semantic context effects in word recognition: An analysis of semantic strategies. Memory \& Cognition, 1980, 8, 493-512.

Becker, C. A., \& Killion, T. M. Interaction of visual and cognitive effects in word recognition. Journal of Experimental Psychology: Human Perception and Performance, 1977, 3, 389-401.

Boddy, J., \& Weinberg, H. Brain potentials, perceptual mechanism and semantic categorization. Biological Psychology, $1981,12,43-61$.

Bouma, H., \& DEVOOgD, A. H. On the control of eye saccades in reading. Vision Research, 1974, 14, 273-284.

Bradley, D. C. Computational distinctions of vocabulary type. Unpublished doctoral dissertation, Massachusetts Institute of Technology, 1978.

Bradley, D. C., Garrett, M. E., \& Zurif, E. B. Syntactic deficits in Broca's aphasia. In D. Caplan (Ed.), Biological studies of mental processes. Cambridge, Mass: MIT Press, 1980.

Carpenten, P. A., \& Daneman, M. Lexical retrieval and error recovery in reading: A model based on eye fixations. Journal of Verbal Learning and Verbal Behavior, 1981, 20, 137-160.

Carpenter, P. A., \& Just, M. A. Cognitive processes in reading: Models based on reader's eye fixations. In A. M. Lesgold \& C. A. Perfetti (Eds.), Interactive processes in reading. Hillsdale, N.J: Erlbaum, 1981.

Cole, R. A., \& JAkimix, J. Understanding speech: How words are heard. In G. Underwood (Ed.), Strategies of information processing. London: Academic Press, 1978.

ColE, R. A., \& JAKImIK, J. A model of speech perception. In R. Cole (Ed.), Perception and production of fluent speech. Hillsdale, N.J: Erlbaum, 1980.

Courchesne, E., Courchesne, R. Y., \& Hillyard, S. A. The effect of stimulus deviation on $P 3$ waves to easily recognizable stimuli. Neuropsychologia, 1978, 16, 189-199.

Courche8ne, E., Hillyard, S. A., \& Galambos, R. Stimulus novelty, task relevance, and the visual evoked potential in man. Electroencephalography and Clinical Neurophysiology, 1975, 39, 131-143.

Danks, J. H. Grammaticalness and meaningfulness in the comprehension of sentences. Journal of Verbal Learning and Verbal Behavior, 1969, 8, 687-696.

Danks, J. H., \& Hill, G. O. An interactive analysis of oral reading. In A. M. Lesgold \& C. A. Perfetti (Eds.), Interactive processes in reading. Hillsdale, N.J: Erlbaum, 1981.

Donchin, E., Ritten, W., \& McCallum, W. C. Cognitive psychophysiology: The endogenous components of the ERP. In E. Callaway, P. Tueting, \& S. Koslow (Eds.), Event-related brain potentials in man. New York: Academic Press, 1978.

Drewnowski, A., \& Healy, A. F. Detection errors on the and and: Evidence for reading units larger than the word. Memory \& Cognition, 1977, 5, 636-647.

Ehrlich, S. F., \& Rayner, K. Contextual effects on word perception and eye movements during reading. Journal of Verbal Learning \& Verbal Behavior, 1981, 20, 641-655.

Fischler, I., \& Bloom, P. A. Automatic and attentional processes in the effects of sentence contexts on word recognition. 
Journal of Verbal Learning \& Verbal Behavior, 1979, 18, 1-20.

Fischler, I., Bloom, P. A., Childers, D. A., Roucos, S. E., \& Perry, N. W., JR. Potentials related to sentence verification. Psychophysiology, 1983, 20, 400-409.

Fond, J. M., \& Hillyand, S. A. ERPS to interruptions of a steady rhythm. Psychophysiology, 1981, 18, 322-330.

Forster, K. I. Accessing the mental lexicon. In E. C. T. Walker \& R. J. Wales (Eds.), New approaches to language mechanism. Amsterdam: North-Holland, 1976.

Friederici, A. D., \& Schoenle, P. W. Computational dissociation of two vocabulary types: Evidence from aphasia. Neuropsychologia, 1980, 18, 11-20.

Friedman, D., Simson, R., Ritter, W., \& Rapin, I. The late positive component (P300) and information processing in sentences. Electroencephalography and Clinical Neurophysiology, $1975,38,255-262$.

Gordon, B., \& Caramazza, A. Lexical decision for open and closed-class words: Failure to replicate differential frequency sensitivity. Brain and Language, 1982, 15, 143-160.

HABER, R. N., \& Schindler, R. Errors in proofreading: Evidence of syntactic control of letter processing? Journal of Experimental Psychology: Human Perception and Performance, $1981,7,573-579$.

JACoBson, J. Z. Effects of association upon masking and reading latency. Canadian Journal of Psychology, 1973, 27, 58-69.

JASPER, H. H. Report of the committee on methods of clinical examination in electromyography. Electroencephalography and Clinical Neurophysiology, 1958, 10, 370-375.

Just, M. A., \& Carpenter, P. A. A theory of reading: From eye fixations to comprehension. Psychological Review, 1980, 87, 329-354.

KEAN, M.-L. The linguistic interpretation of aphasic syndromes: Agrammatism in Broca's aphasia, an example. Cognition, 1977 , $5,19-46$.

Kleiman, G. M. Sentence frame context and lexical decisions: Sentence-acceptability and word-relatedness effects. Memory \& Cognition, 1980, 8, 336-344.

Kutas, M., \& Hilly ARD, S. A. Event-related brain potentials to semantically inappropriate and surprisingly large words. Biological Psychology, 1980, 11, 99-116. (a)

KutAs, M., \& Hillyard, S. A. Reading between the lines: Eventrelated brain potentials during natural sentence processing. Brain and Language, 1980, 11, 354-373. (b)

KuTAS, M., \& Hillyard, S. A. Reading senseless sentences: Brain potentials reflect semantic incongruity. Science, 1980, 207, 203-205. (c)

Kutas, M., \& Hillyard, S. A. The lateral distribution of eventrelated potentials during sentence processing. Neuropsychologia, $1982,20,579-590$

Kutas, M., \& Hillyard, S. A. Event-related brain potentials (ERPs) elicited by "novel" stimuli during sentence processing. In R. Karrer, J. Cohen, \& P. Tueting (Eds.), Brain information: Event-related potentials. New York Academy of Sciences, New York. Monograph 12, in press.

Kutas, M., Lindamood, T. E., \& Hillyard, S. A. Word expectancy and event-related brain potentials during sentence processing. In S. Kornblum \& J. Requin (Eds.), Preparatory states and processes. Hillsdale, N.J: Erlbaum, in press.

Kutas, M., McCarthy, G., \& Donchin, E. Augmenting mental chronometry. Science, 1977, 197, 792-795.

Marks, L. E., \& Miller, G. A. The role of semantic and syntactic constraints in the memorization of English sentences. Journal of Verbal Learning \& Verbal Behavior, 1964, 3, 1-5.

Marslen-Wilson, W. D. Sentence perception as an interactive parallel process. Science, 1975, 189, 226-228.

Marglen-Wilson, W. D., \& Tyler, L. K. Processing structure of sentence perception. Nature, 1975, 257, 784-786.

Marslen-Wilson, W. D., \& TYler, L. K. The temporal structure of spoken language understanding. Cognition, 1980, 8, $1-71$.

Marslen-Wilson, W. D., Tyler, L. K., \& Seidenberg, M.
Sentence processing and the clause-boundary. In W. J. M. Levelt \& G. B. Flores D'Arcais (Eds.), Studies in sentence perception. New York: Wiley, 1978.

Marslen-Wilson, W. D., \& Welsh, A. Processing interactions and lexical access during word recognition incontinuous speech. Cognitive Psychology, 1978, 10, 29-63.

MoConkie, G. W., Zola, D., Blanchard, H. E., \& Wolverton, G. S. Perceiving words during reading: Lack of facilitation from prior peripheral exposure. Perception \& Psychophysics, 1982, 32, 271-281.

Meyer, D. E., Schvaneveldt, R. W., \& Ruddy, M. G. Loci of contextual effects on word recognition. In P. M. A. Rabbitt \& S. Dornic (Eds.), Attention and performance $V$. New York: Academic Press, 1975.

Moore, T. E., \& Biederman, I. Speeded recognition of ungrammaticality: Double violations. Cognition, 1979, 7, 285-299.

Monton, J. The effects of context on the visual duration threshold for words. British Journal of Psychology, 1964, 55, 165-180.

Morton, J. The logogen model and orthographic structure. In $\mathrm{U}$. Frith (Ed.), Cognitive processes in spelling. London: Academic Press, 1980.

Nátanen, R., Gaillard, A. W. K., \& Mantysalo, S. Brain potential correlates of voluntary and involuntary attention. In H. H. Kornhuber \& L. Deecke (Eds.), Motivation, motor and sensory processes of the brain, progress in brain research (Vol. 54). Elsevier/North-Holland, 1980.

NaAtanen, R., Simpson, M., \& Loveless, N. E. Stimulus deviance and evoked potential. Biological Psychology, 1982, 14, 53-98.

Neville, H. J., Kutas, M., \& Schmidt, A. Event-related potential studies of cerebral specialization during reading. I: Studies of normal adults. Brain and Language, 1982, 16, 300-315.

Neville, H. J., Snyder, E., Woods, D. L., \& Galambos, R. Recognition and surprise alter the human visual evoked response. Proceedings of the National Academy of Sciences, 1982, 79, 2121-2123.

OldField, R. C. The assessment and analysis of handedness: The Edinburgh Inventory. Neuropsychologia, 1971, 9, 97.113.

Polich, J., Vanasse, L., \& Donchin, E. Category expectancy and the N200. Psychophysiology, 1981, 18, 142.

Pritchard, W. S. Psychophysiology of P300. Psychological Bulletin, 1981, 89, 506-540.

Ritter, W., Ford, J., Gaillard, A., Harter, R., Kutas, M., Naatanen, R., Polich, J., Renault, B., \& Rohrbaugh, J. Cognition and event-related potentials: The relation of negative potentials and cognitive processes. In R. Karrer, J. Cohen, \& P. Tueting (Eds.), Brain information: Event-related potentials. New York Academy of Sciences, New York. Monograph 12, in press.

Ritter, W., Simson, R., Vaughan, H. G., Jr. Event-related potential correlates of two stages of information processing in physical and semantic discrimination tasks. Psychophysiology, 1983, 20, 168-179.

Ritter, W., Simson, R., Vaughan, H. G., Jr., \& Friedman, D. A brain event related to the making of a sensory discrimination. Science, 1979, 203, 1358-1361.

Roth, W. T., Ford, J. M., \& KopelL, B. S. Long-latency evoked potentials and reaction time. Psychophysiology, 1978, 15, 17-23.

Schindler, R. M. The effects of prose context on visual search for letters. Memory \& Cognition, 1978, 6, 124-130.

Schuberth, R. E., \& Eimas, P. D. Effects of context on the classification of words and nonwords. Journal of Experimental Psychology: Human Perception and Performance, 1977, 3, 27-36.

Schuberth, R. E., Spoemr, K. T., \& Lane, D. M. Effects of stimulus and contextual information on the lexical decision process. Memory \& Cognition, 1981, 9, 68-77.

Shannon, B. Interpretation of ungrammatical sentences. Journal of Verbal Learning and Behavior, 1973, 12, 389-400.

Shelburne, S. A., JR. Visual evoked responses to word and nonsense syllable stimuli. Electroencephalography and Clinical Neurophysiology, 1972, 32, 17-25. 
Simbon, R., Vaughan, H. G., JR., \& Ritter, W. The scalp topography of potentials in auditory and visual discrimination tasks. Electroencephalography and Clinical Neurophysiology, 1977, 12, 528-535.

SNYDER, E., \& Hillyard, S. A. Long-latency evoked potentials to irrelevant deviant stimuli. Behavioral Biology, 1976, 16, 319-331.

Squires, N. K., Squires, K. C., \& Hillyard, S. A. Two varieties of long-latency positive waves evoked by unpredictable auditory stimuli. Electroencephalography and Clinical Neurophysiology, 1975, 38, 387-401.

Stanovich, K. E. Attention and automatic context effects in reading. In A. M. Lesgold \& C. A. Perfetti (Eds.), Interactive processes in reading. Hillsdale, N.J: Erlbaum, 1981.

Stanovich, K. E., \& West, R. F. Mechanisms of sentence context effects in reading: Automatic activation and conscious attention. Memory \& Cognition, 1979, 7, 77-85.

Stanovich, K. E., \& WEst, R. F. The effect of sentence context on ongoing word recognition: Tests of a two-process theory. Journal of Experimental Psychology: Human Perception and Performance, 1981, 7, 658-672.

Stuss, D. T., Sarazin, F., Leech, E., \& Picton, T. W. Evoked potentials during naming. In R. Karrer, J. Cohen, \& P. Tueting (Eds.), Brain information: Event-related potentials. New York Academy of Sciences, New York. Monograph 12, in press.

Swinney, D. A., Zurif, E. B., \& Cutler, A. Effects of sentential stress and word class upon comprehension in Broca's aphasia. Brain and Language, 1980, 10, 132-144.

Tulving, E., \& Gold, C. Stimulus information and contextual information as determination of tachistoscopic recognition of words. Journal of Experimental Psychology, 1963, 66, 319-327.

Tylen, L. K., \& Marsien-Witson, W. D. The on-line effects of semantic context on syntactic processing. Journal of Verbal Learning \& Verbal Behavior, 1977, 16, 683-692.

TyLer, L. K., \& MARsLen-Wilgon, W. D. Children's processing of spoken language. Journal of Verbal Learning \& Verbal Behavior, 1981, 20, 400-416.

UNDERWOOD, G., \& BARGH, K. Word shape, orthographic regularity, and contextual interactions in a reading task. Cognition, 1982, 12, 197-209.

WANG, M. D. Influence of linguistic structure on comprehensibility and recognition. Journal of Experimental Psychology, 1970, 85, 83-89.

ZURIF, E. B. Language mechanisms: A neuropsychological perspective. American Scientist, 1980, 68, 305-311.

\section{NOTES}

1. The comparison ERP for nouns with incorrect number (left column) and for verbs with incorrect tense (right column) was the same as that chosen for the intermediate semantic anomalies-that is, the average of the content words immediately preceding each deviation. The comparison ERP for the verbs with incorrect number (middle column) was averaged over all types of words that immediately preceded them; these turned out to be approximately $50 \%$ content and $50 \%$ function words, about the same proportion as for the grammatically deviant category itself.

2. The $400-700-\mathrm{msec}$ rather than the $200-700-\mathrm{msec}$ epoch was chosen for the analysis of lateral distribution in order to be consistent with previous investigations of this effect (see Kutas \& Hillyard, 1980a, 1980b, in press).

3. Recently, Ritter, Simson, \& Vaughan (1983) reported a late negative component (peaking around $300 \mathrm{msec}$ ) with little or no ensuing positivity in response to an infrequent physical stimulus (20\%) within a Bernoulli sequence, under conditions in which subjects were required to respond to all stimuli with a simple reaction time. However, it is difficult to verify the absence of a subsequent $P 300$ component in these ERPs, because the analysis epoch lasted only $500 \mathrm{msec}$ and parietal recordings were not shown (see their Figure 9).
APPENDIX

Representative Incongruities

\section{A. Sentence Terminal Semantic Anomalies}

1. Most turtles eat regularly when they can but some are able to go a year without paint.

2. When baby turtles hatch, they are about two inches long and look something like their scissors.

3. The soft shelled turtle has such a long neck, it can get air without leaving the peach.

4. Cold air at one height has more pressure than warm air at the same pencil.

5. Sometimes a tornado is only a few hundred feet wide. Its winds go round and square.

6. Most turtles have no voice but a few can make barks or doors.

7. The leopard is a very good napkin.

B. Sentence Intermediate Semantic Anomalies

1. The mouth has a hard horny beak with cutting ovens instead of teeth.

2. Others eat leaves, radios, and various plant parts.

3. Sometimes the diamondback swims in the open sea but it usually lives in salt shakers and tidal rivers.

4. A little bit of weather happens in the lower boat of the stratosphere.

5. A low often brings kittens or snow.

6. The cougar is one of the largest American cats. It can leap from great measles and bound across the ground.

7. Bobcats hunt mice, squirrels, rabbits, laughs, and many other small animals.

\section{Grammatical Error-Noun Number}

1. All turtles have four leg and a tail but some have very different feet.

2. In Africa there is a small soft shelled tortoises that lives among rocks.

3. This tortoise takes in air and swells up like a balloons so that it becomes safely fastened in the crevice.

4. When air moves it of ten moves in a big bodies hundreds of miles wide called an air mass.

5. The ice grows and grows until it forms a six sided flakes that we can see.

6. Some storms have thunders and lightning.

7. The leopard uses its long tails to help it keep its balance.

D. Grammatical Error-Verb Number

1. Then she dig a hole with her rear feet.

2. Turtles will spit out things they does not like to eat.

3. Its shell may varies from light brown to black.

4. Air is mostly heated or cooled by the land it move over.

5. But when the wind blows we knows that the air has pressure because we feel it pushing us.

6. When cats is climbing or fighting they put out their claws.

7. Their eyes glow and their pupils grows big and round.

\section{E. Grammatical Error-Verb Tense}

1. Most of the earth's weather happens in the bottom layer of the atmosphere calls the troposphere.

2. The eggs and meat of this turtle are consider choice food by many people.

3. This allows them to stayed under water for a longer period.

4. It may moved over land and water for a long way.

5. It has very powerful winds that can caused great damage.

6. Ait does not always had the same humidity.

7. If the air is so full of water vapor that it cannot held any more then the weather report says that the relative humidity is one hundred percent.

(Manuscript received November 11, 1982;

revision accepted for publication March 24, 1983.) 